\title{
C-Reactive Protein in Guillainbarré Syndrome: Recent Advances and Future Prospective
}

\author{
Dharambeer Singh Mahor ${ }^{1}$, AnjuMahor ${ }^{2}$ and Mayadhar Barik ${ }^{2 *}$ \\ ${ }^{1}$ Department of Laboratory Medicine, India \\ ${ }^{2}$ Department of Microbiology, India
}

Submission: March 15, 2018; Published: September 14, 2018

"Corresponding author: Mayadhar Barik, Senior Scientific Advisor, Editor-in-Chief, Department of Microbiology, Clin Diag, India, Email: mayadharbarik@gmail.com

\begin{abstract}
Introduction: C-reactive protein (CRP) is an acute phase reactant (APR), which is widely used as a potential biomarker in various infectious and inflammatory conditions (IICs). C-reactive protein (CRP) is also responsible for the Guillain-Barré syndrome (GBS).
\end{abstract}

Aim and Objectives: C-reactive protein (CRP) levels were estimated in sera of patients with GBS and compared with adequate healthy controls from 2014 to 2018 from our locality.

Settings and Design: This is a prospective-control study from (2014-2018) from our locality.

Study Population: This study divided into 4 groups: 1 . GBS group included 50 newly diagnosed patients with GBS; 2 . Neurological control (NC) group comprised of 50 patients with non-paralytic neurological symptoms/disorders (NPNS); 3. Non-neurological controls (NNC) comprised of 50 patients having no neurological symptoms and 4. Healthy controls group (HCP) comprised of 150 healthy subjects.

Materials and Methods: C-reactive protein (CRP) was evaluated by slide latex agglutination test (SLAT) and enzyme linked immunosorbent assay (ELISA) through available kits in the market or available from the noted company.

Statistical Analysis: We used the very simple and descriptive statistics through available software in SPSS Statistics versions 16.0.

Results: CRP by LAT was positive in $25.8 \%$ GBS group, 35.5\% NC group and $45.6 \%$ NNC group. The range of titer in CRP positive samples in the three patient groups (GBS, NC, NNCG) was at concentration of $0.5 \mathrm{mg} / \mathrm{dl}$ to $19.5 \mathrm{mg} / \mathrm{dl}$. The similar results were also obtained by ELISA in the patient groups (PGs). None of the HC subjects was positive for detectable levels of CRP were observed. Additionally, the Higher basal level (HBL) of CRP was detected in patients with GBS successfully.

Conclusion: Autoimmune conditions like Guillain-Barré syndrome (GBS) can stimulate the production of a higher level of inflammation rate (HLIR) resulted through C-reactive protein (CRP) is a unique biomarker for the Bilateral facial nerve palsy (BFNP) or facial diplegia (FD) is a rare condition that occurs mainly in the context of Guillain-Barré syndrome (GBS).

Keywords: C-reactive protein; Guillain-Barré syndrome; Slide latex agglutination test; Enzyme linked immunosorbent assay; Violent systemic autoimmune reaction

Abbreviations: CRP: C-Reactive Protein; IICs: Infectious and Inflammatory Conditions; APR: Acute Phase Reactant; GBS: Guillain-BarréSyndrome; HIPM: Humoral Immuno Pathogenic Mechanism; AAID: Acute Autoimmune Disorder; HBL: Higher Basal Level; AITs: Autoimmunological Titers; PLR: Prolonged Leukemoid Reaction; Rf: Rheumatoid Factor; ANCA: Antineutrophil Cytoplasmic Autoantibody; ARDS: Acute Respiratory Distress Syndrome; MS: Multiple Sclerosis; MI: Myocardial Ischemia; COPD: Chronic Obstructive Pulmonary Disease; TD: Tissue detection; TAIA: Therapeutic Anti-Inflammatory Agent; DOMs: Dissemination of Microorganisms; FI: Focal Infection; EC: Eredo-Constitutionality; ALS: Amyotrophic Lateral Sclerosis

\section{Introduction}

C-reactive protein (CRP) is an acute phase reactant (APR), used as a biomarker for various infectious and inflammatory conditions (IICs) [1]. Guillain-Barré syndrome (GBS) is an acute autoimmune, polyradiculoneuropathy (PRNP)triggered by infectious agents such as Campylobacter jejuni [2]. GBS is generally precipitated with 1-3 weeks following C. jejuni

infection and suggests a humoral immunopathogenic mechanism (HIPM) [3]. The incidence rates of pyrexia, headache, nausea, gastro interological (GI) problems with GBS is related to acute autoimmune disorder (AAID) still unknown [4]. CRP levels were estimated within these of patients with GBS and compared with adequate controls and range of titer in CRP positive samples [5]. The three major patient groups (GBS, NC, NNC) were at 
concentration of $0.6 \mathrm{mg} / \mathrm{dl}$ to $19.2 \mathrm{mg} / \mathrm{dl}$. The higher basal level (HBL) of CRP was also detected in patients with GBS [6]. In Blood plasma exchange had been given as violent immunological reaction (VIR) was unable to control the acute motor axonal neuropathy (AMAN) and GBS [5]. Prolonged leukemoid reaction (PLR) and higher level of autoimmunological titers (AITs), including C-reactive protein (CRP), rheumatoid factor (Rf), and antineutrophil cytoplasmic autoantibody (ANCA) also persisted with GBS [7]. Patient developed with acute respiratory distress syndrome (ARDS) and type 3 of rapidly progressive glomerulonephritis (RPGN) rapidly declined of renal function (RF) and immune suppressants were still not documented [8]. AMAN with the violent systemic autoimmune reaction (VSAIR) is strongly associated with infectious disease GBS [9]. GBS patients were implied with standard plasmapheresis (SPP) is insufficient and corticosteroids with immunosuppressant added in early stage of GBS is still a research question with (AMAN) [10].

\section{Materials and Methods}

\section{Aim and objectives}

C-reactive protein (CRP) levels were estimated in sera of patients with GBS and compared with adequate healthy controls from 2014 to 2018 from our locality/local area and informed.

\section{Settings and design}

This is a prospective-control study from (2014-2018) from our locality in prospective way.

\section{Study population}

This study we divided into 4 groups: 1 . GBS group included 50 newly diagnosed patients with GBS; 2 . Neurological control (NC) group comprised of 50 patients with non-paralytic neurological symptoms/disorders (NPNS) 3. Non-neurological controls (NNC) comprised of 50 patients having no neurological symptoms and 4. Healthy controls group (HCP) comprised of 150 healthy subjects on prior order.

\section{Inclusion criteria}

Who is willing to the study subject were included in this study.

\section{Exclusion criteria}

Those unwilling to this study subject were strictly excluded from our study.

\section{Materials and methods}

C-reactive protein (CRP) was evaluated by slide latex agglutination test (SLAT) and enzyme linked immunosorbent assay (ELISA) through available kits in the market or available from the noted company according to International standard protocol.

\section{Statistical analysis}

We used the very simple and descriptive statistics through available software in SPSS Statistics versions 16.0. Available on online and down loaded freely available.

\section{Results}

According to our findings of CRP by LAT was positive in $25.8 \%$ GBS group, $35.5 \%$ NC group and $45.6 \%$ NNC group. The range of titer in CRP positive samples in the three patient groups (GBS, NC, NNCG) was at concentration of $0.5 \mathrm{mg} / \mathrm{dl}$ to $19.5 \mathrm{mg} /$ $\mathrm{dl}$. The similar results were also obtained by ELISA in the patient groups (PGs). None of the healthy control (HC) subjects was positive for detectable levels of CRP were observed. Additionally, the Higher basal level (HBL) of CRP was detected in patients with GBS successfully is our one of the great achievements in this study groups. LAT was positive in $25.8 \%$ and its nearly related results obtained from other confirmatory test in another laboratory from our seniors give the strength of this report in our study and verify our both reports.

\section{Discussion}

$\alpha B$-crystallin (HspB5) is a chaperone and a potential biomarker of innate immunity activation (IIA)for GBS [11]. Therapeutic potential had been investigated in several inflammatory diseases (multiple sclerosis (MS), myocardial ischemia (MI), and Guillain-Barré syndrome (GBS) and obstructive pulmonary disease (COPD) pathogenesis and their inflammation [12]. Tissue detection (TD) of the protein showed significantly overexpressed in COPD smokers in comparison to COPD nonsmokers expressed in patients with age-related emphysema [13]. $\alpha \mathrm{B}$-crystallin is a regulator of innate immunity (II) and a therapeutic anti-inflammatory agent (TAIA) [14]. Focal infection (FI), has been localized or generalized infection caused by the dissemination of microorganisms (DOMs) or toxic products from a focus of infection in organic districts [15]. An "immuno-allergic theory" with formation of auto-antibodies in human body, genesis of autoimmune illnesses (AIIs) sustained by individual reactivity (IR) linked to eredo-constitutionality (EC) [16]. The focal origin pathology (FOP), are cancer, sarcoidosis, multiple sclerosis (MS), amyotrophic lateral sclerosis (ALS), autism and Guillain-Barré syndrome (GBS) [17]. An Autoimmune Neuropsychiatric Disorders (AINPDs) were associated with Streptococcal infections (PANDAS), Tourette's syndrome (TS), myasthenia gravis (MG), polycystic kidney disease (PKD), obesity, Alzheimer's disease (AD) and diabetes mellitus (DM) among pediatric test had performed through by the Laboratory test analyses (LTA) is one of the important and strictly, priority basis test (PBT) [18].

Leucocytic formula (LF), protein electrophoresis (PE), Gel analysis, C-reactive protein, REUMA test VES, TAS, were the test of an inflammatory process (IP). The DNA-Polymerase Chain Reaction method (PCR) and Real time Polymerase Chain Reaction method (RT-PCR) is the fundamental test for the diagnosis of bacterial and viral infections (BVIs) [19]. An intensive periodontal therapy (IPT) also showed a significant reduction of lymphocyte formula at CRP levels of interleukin-6 (IL-6), (IL-8), Polymorphisms of IL-17 and ICAM-1 and their expression and the LDL cholesterol after two-three months of GBS [20]. Fever and acute respiratory failure (FARF), progressive tetra paresis, 
delirium (PTD), behavioral abnormalities (BA), and diplopia [21]. At Leukocytosis had increased the C-reactive protein (CRP), present in appropriate anti-diuretic hormone secretion (SIADH) [22]. The Lumbar puncture (LP), yielded colorless CFS with mononuclear pleocytosis (MNP) and Regulatory $\mathrm{T}$ cell frequency, but not plasma IL-33 levels the protein rises in axonal degeneration (AD) [23]. An Electrodiagnosis test revealed that demyelinating polyneuropathy (DMPN) and axonal degeneration (AD) [24]. The serum IgG and IgM for mycoplasma pneumoniae (MP) was consistent with acute infection (AI), erythromycin has been started with rapid resolution (RR) of the symptoms [25]. Respiratory disease (RD) were not present and SIADH, patient without the direct central nervous system (DCNS) involvement, differential diagnosis (DD) and possible pathogenic mechanisms (PPM) involved in Guillain-Barré syndrome (GBS) [26].

\section{Recent advances and future prospective}

ST-segment elevation (STSE) noted in association with reversible left ventricular dysfunction (LVD) due to the synergistic toxic effect (STE) [27]. An increased catecholamine and transiently damaged sympathetic nerve (DSN) endings at the myocardium in Guillain-Barré syndrome (GBS) [28]. Importantly, causative Hantaviral serotype (HVST), the degree of "systemic inflammatory response syndrome" (SIRS) responsible to determine the clinical picture in Hantavirus infections and associated diseases of GBS [29]. GBS can stimulate the production of a higher level of inflammation (HLOI), increase in the CRP production on Bilateral facial nerve palsy (BLFP) or facial diplegia (FD) distinctively. We report patients with isolated idiopathic bilateral facial nerve palsy (IIBFNP), with meningitis having no evidence of Guillain-Barré syndrome (GBS) and Comparative Value of Erythrocyte Sedimentation Rate (ESR) and C-Reactive Protein (CRP) rapid and complete recovery till date [30].

\section{Conclusion}

We concluded that an unusual variant of bilateral facial palsy (UVBFP), Acute motor axonal neuropathy (AMAN), Guillain Barre syndrome (GBS), is frequently induced by the antecedent infection via atypical pathogen, such as Campylobacter jejuni, Mycoplasma pneumonia and some viruses generally accepted that corticosteroids and immunosuppressants are not recommended in patients with (GBS including AMAN). Autoimmune conditions like Guillain-Barré syndrome (GBS) can stimulate the production of a higher level of inflammation rate (HLIR) resulted through C-reactive protein (CRP). Bilateral facial nerve palsy (BFNP) or facial diplegia (FD) is a rare condition that occurs mainly in the context of Guillain-Barré syndrome (GBS).C-reactive protein (CRP) count as a potential and capable biomarker for such kind of activities.

\section{Acknowledgement}

We thanks to our all seniors for their laboratory help and support.

\section{References}

1. Ma XY, Li Z, Wang XJ, Ye JJ, Ma YP, et al. (2016) Clinical efficacy of different doses of gamma globulin combined with glucocorticoid in treatment of moderate/severe acute Guillain-Barré syndrome in children: a comparative analysis. Zhongguo Dang Dai Er Ke Za Zhi 18(12): 1286-1290.

2. Vaishnavi C, Kapoor P, Behura C, Singh SK, Prabhakar S (2014) C-reactive protein in patients with GuillainBarré syndrome. Indian J Pathol Microbiol 57(1): 51-54.

3. Yu RK, Usuki S, Ariga T (2006) Ganglioside molecular mimicry and its pathological roles in Guillain Barré syndrome and related diseases. Infect Immun 74(12): 6517-6527.

4. Khlebtovsky A, Saban T, Steiner I (2013) Unusual and benign course of idiopathic facial diplegia. J Clin Neurosci 20(6): 904-905.

5. Pepys MB (1995) The acute phase response and C-reactive protein. In: Weatherall DJ, Ledingham JGG, Warrell DA, (eds.) Oxford Textbook of Medicine. ( $3^{\text {rd }}$ edn), Oxford: Oxford University Press, 2: 1527-1533.

6. Hughes RA, Cornblath DR (2005) Guillain Barré syndrome. Lancet 366(9497): 1653-1666.

7. Murphy CL, Bangash IH, Ustianowski A, Varma A (2012) A case of acute neurogenic weakness mimicking the axonal variant of the GuillainBarre syndrome. Pract Neurol 12(6): 371-375.

8. Chen AC, Chen CM, Chang HR, Yeo KJ, Tsao SM, et al. (2013) Complicated acute motor axonal neuropathy with delayed acute respiratory distress syndrome and rapidly progressive glomerulonephritis: a case report. Acta Neurol Taiwan 22(1): 26-31.

9. Ogawara K, Kuwabara S, Mori M, Hattori T, Koga M, et al. (2000) Axonal Guillain-Barré syndrome: relation to anti-ganglioside antibodies and Campylobacter jejuni infection in Japan. Ann Neurol 48(4): 624-631.

10. Yuki N, Kuwabara S (2007) Axonal Guillain-Barré syndrome: carbohydrate mimicry and pathophysiology. J Peripher Nerv Syst 12(4): 238-249.

11. Cherneva RV, Georgiev OB, Petrova DS, Trifonova NL, Stamenova M, et al. (2012) The role of small heat-shock protein $\alpha \mathrm{B}$-crystalline (HspB5) in COPD pathogenesis. Int J Chron Obstruct Pulmon Dis 7: 633-640.

12. Trivedi S, Pandit A, Ganguly G, Das SK (2017) Epidemiology of Peripheral Neuropathy: An Indian Perspective Ann Indian Acad Neurol 20(3): 173-184.

13. Kim JE, Kim JK, Park KM, Kim Y, Yoon DY, et al. (2016) Top-100 cited articles on Guillain-Barré syndrome: a bibliometric analysis. J Peripher Nerv Syst 21(4): 329-338.

14. Ning P, Guo YF, Sun TY, Zhang HS, Chai D, et al. (2016) Study of the clinical phenotype of symptomatic chronic airways disease by hierarchical cluster analysis and two-step cluster analyses 55(9): 679-683.

15. Zhang Y, Chen Y, Wu J, Manaenko A, Yang P, et al. (2015) Activation of Dopamine D2 Receptor Suppresses Neuroinflammation Through $\alpha \mathrm{B}$-Crystalline by Inhibition of NF-kB Nuclear Translocation in Experimental ICH Mice Model. Stroke 46(9): 2637-2646.

16. Somma F, Castagnola R, Bollino D, Marigo L (2010) Oral inflammatory process and general health. Part 1: The focal infection and the oral inflammatory lesion. Eur Rev Med Pharmacol Sci 14(12): 1085-1095.

17. Bach JF (2005) Infections and autoimmune diseases. J Auto immun 25 Suppl: 74-80.

18. Wijdicks EFM, Klein CJ (2017) Guillain-Barre syndrome. Mayo Clin Proc 92(3): 467-469.

19. (2017) Guillain-Barre syndrome fact sheet. National Institute of Neurological Disorders and Stroke.

20. Vriesendorp FJ (2017) Guillain-Barre syndrome: Pathogenesis. 
21. Kharwar NK, Prasad KN, Singh K, Paliwal VK, Modi DR (2017) Polymorphisms of IL-17 and ICAM-1 and their expression in GuillainBarré syndrome. Int J Neurosci 127(8): 680-687.

22. Brooks PT, Brakel KA, Bell JA, Bejcek CE, Gilpin T, et al. (2017) Transplanted human fecal microbiota enhanced Guillain Barré syndrome auto antibody responses after Campylobacter jejuni infection in C57BL/6 mice. Microbiome 5: 92.

23. Akil E, Bulut A, Kaplan I, Ozdemir HH, Arslan D, et al. (2015) The increase of carcinoembryonic antigen (CEA), high-sensitivity C-reactive protein, and neutrophil/lymphocyte ratio in Parkinson's disease. Neurol Sci 36(3): 423-428.

24. Maddur MS, Stephen-Victor E, Das M, Prakhar P, Sharma VK, et al. (2017) Regulatory $\mathrm{T}$ cell frequency, but not plasma IL-33 levels, represents potential immunological biomarker to predict clinical response to intravenous immunoglobulin therapy. J Neuroinflammation 14: 58.

25. Hiraga A, Mori M, Ogawara K, Kojima S, Kanesaka T, et al. (2005) Recovery patterns and long term prognosis for axonal Guillain-Barre syndrome. Journal of neurology, neurosurgery, and psychiatry 76(5): 719-722.

This work is licensed under Creative Commons Attribution 4.0 License DOI: 10.19080/ARGH.2018.10.555791
26. Coelho M, Leite A, Revés A, Miranda C, Serra I, et al. (2004) Mycoplasma pneumoniae causing nervous system lesion and SIADH in the absence of pneumonia. Clin Neurol Neurosurg 106(2): 129-131.

27. Iga K, Himura Y, Izumi C, Miyamoto T, Kijima K, et al. (1995) Reversible left ventricular dysfunction associated with Guillain-Barré syndrome-an expression of catecholamine cardiotoxicity? 59(4): 236-240.

28. Arbel Y, Finkelstein A, Halkin A, et al. (2012) Neutrophil/lymphocyte ratio is related to the severity of coronary artery disease and clinical outcome in patients undergoing angiography. Atherosclerosis 225(2): 456-460.

29. Tassart G, Balbeur S, Deltombe T, Tintillier M, Cuvelier Ch, et al. (2014) Guillain-Barré syndrome associated with Puumula Hantavirus infection. Acta Clin Belg 69(5): 371-374.

30. Assasi N, Blackhouse G, Campbell K, et al. (2015) Comparative Value of Erythrocyte Sedimentation Rate (ESR) and C-Reactive Protein (CRP) Testing in Combination Versus Individually for the Diagnosis of Undifferentiated Patients with Suspected Inflammatory Disease or Serious Infection: A Systematic Review and Economic Analysis. Ottawa $(\mathrm{ON})$.

\section{Your next submission with JuniperPublishers will reach you the below assets}

- Quality Editorial service

- Swift Peer Review

- Reprints availability

- E-prints Service

- Manuscript Podcast for convenient understanding

- Global attainment for your research

- Manuscript accessibility in different formats

( Pdf, E-pub, Full Text, audio)

- Unceasing customer service

Track the below URL for one-step submission https://juniperpublishers.com/online-submission.php 